\title{
Progress and current trends in the synthesis of novel polymers with enhanced mucoadhesive properties
}

Article

Accepted Version

Brannigan, R. P. and Khutoryanskiy, V. V. (2019) Progress and current trends in the synthesis of novel polymers with enhanced mucoadhesive properties. Macromolecular Bioscience, 19 (10). e1900194. ISSN 1616-5187 doi: https://doi.org/10.1002/mabi.201900194 Available at https://centaur.reading.ac.uk/85336/

It is advisable to refer to the publisher's version if you intend to cite from the work. See Guidance on citing.

To link to this article DOI: http://dx.doi.org/10.1002/mabi.201900194

Publisher: Wiley

All outputs in CentAUR are protected by Intellectual Property Rights law, including copyright law. Copyright and IPR is retained by the creators or other copyright holders. Terms and conditions for use of this material are defined in the End User Agreement.

www.reading.ac.uk/centaur 
Central Archive at the University of Reading

Reading's research outputs online 


\title{
Progress and Current Trends in the Synthesis of Novel Polymers with Enhanced Mucoadhesive Properties
}

\author{
Ruairí P. Brannigan, ${ }^{\mathrm{a}}$ Vitaliy V. Khutoryanskiy ${ }^{\mathrm{b}^{*}}$ \\ aDepartment of Chemistry, RCSI, 123 St Stephens Green, Dublin 2, Ireland. \\ ${ }^{\mathrm{b}}$ School of Pharmacy, University of Reading, Whiteknights, PO Box 224, Reading, RG6 6AD, \\ UK.
}

\section{CORRESPONDING AUTHOR}

*Email: $\underline{\text { V.Khutoryanskiy@ reading.ac.uk }}$

KEY WORDS: Mucoadhesion, mucoadhesive polymers, water-soluble polymers, thiomers, catechol, maleimide, acrylate

\section{ABSTRACT:}

Mucoadhesion is defined as the adherence of a synthetic or natural polymer to a mucosal membrane via physical or chemical interactions. Mucoadhesive materials are widely used to develop dosage forms for transmucosal drug delivery via ocular, nasal, esophageal, oral, vaginal, rectal and intravesical routes of administration. This review will discuss some of the most prominent and recent synthetic methodologies employed to modify polymeric materials in order to enhance their mucoadhesive properties. This includes chemical conjugation of polymers with molecules bearing thiol-, catechol-, boronate-, acrylate-, methacrylate-, maleimide- and N-hydroxy(sulfo)succinimide ester- groups. 


\section{Introduction to mucosae and mucoadhesion}

\section{Mucosae and mucin}

Mucosae or mucous membranes are defined as moist tissue linings which envelop all cavities and canals which communicate with the exterior i.e. the eyes, gastrointestinal tract, genitourinary tract, respiratory passages consisting of a mucus covered outer epithelial layer and a sub-layer of connective tissue (lamina propria) which form a protective barrier for underlying structures. ${ }^{[1]}$ The surface epithelial stratum can present itself as either a single layered (bronchi, stomach and intestine) or multi-layered (cornea, oesophagus, vagina) structure which, in the latter instance, contains or are neighboured by dedicated glands which secrete mucus onto the epithelia i.e. submucosal esophageal glands/esophageal cardiac glands present in the oesophagus. Additionally, cavities or canals consisting of single layered epithelia containing modified columnar epithelial cells, known as goblet cells, which secrete mucus directly onto the outer epithelial layer (Figure 1). ${ }^{[1-3]}$

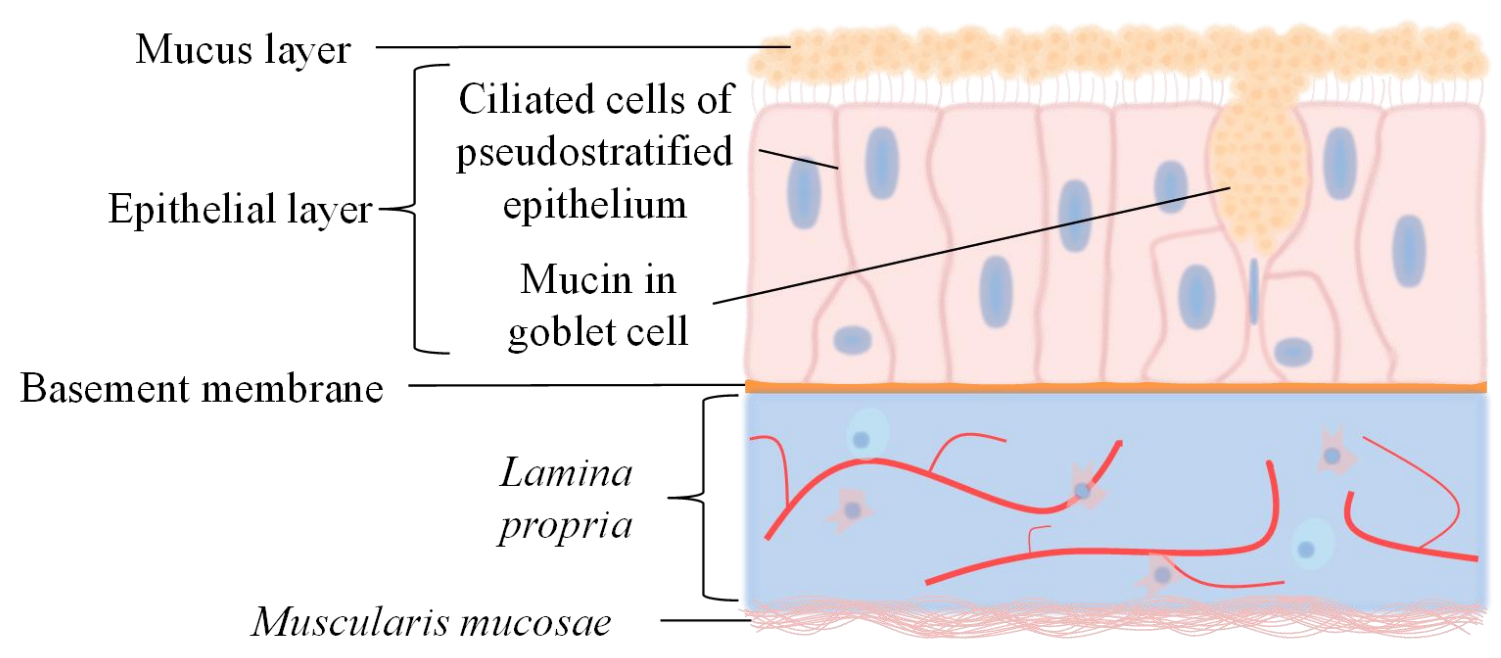

Figure 1. Schematic of mucosal membrane 
Secreted mucus layers are adherent viscous colloidal gels comprising predominantly of extracellular glycoproteins, lipids such as fatty acids, phospholipids, inorganic salts, cholesterol, defensive proteins (i.e. lysosomes, defensins, trefoil factors etc.) and water ( 95\%), in which mucin glycoproteins provide the main structure-forming characteristics of the gel. ${ }^{[4]}$ Mucins are large extracellular glycoproteins (0.5-20 MDa), characteristically consisting of a linear protein 'core', which is $\sim 20 \%$ of the total molecular mass (200-500 kDa) and a partially branched carbohydrate proponent which makes up the remaining $\sim 80 \%$ of the total composition of the mucin glycoprotein. ${ }^{[4-6]}$ These glycoproteins are negatively charged due to the presence of terminal sialic acid (pKa of 2.6) and sulphate groups. ${ }^{[7]}$

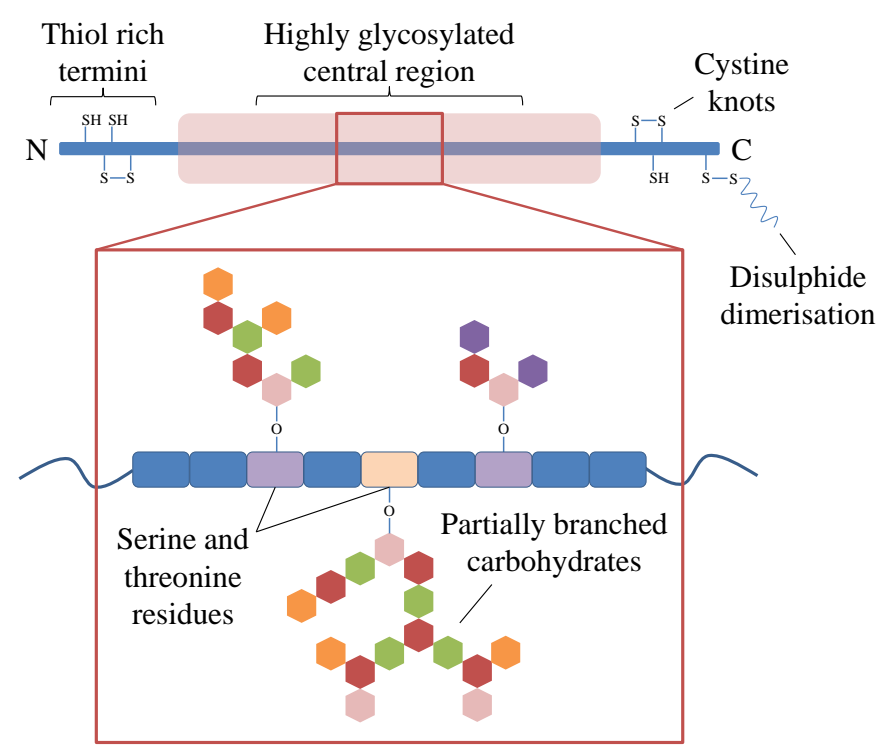

Figure 2. Basic schematic drawing of mucin glycoprotein

The protein core may be broken down into two component regions; the cysteine rich (>10\%) $\mathrm{N}$ - and C- termini 'globular protein-like' regions, involved in the dimerization of mucins through disulphide bond formations, and a highly glycosylated 'bottle-brush' central region consisting of tandemly repeated amino acids abundant in $O$-glycosylated threonine and serine residues (Figure 2) ${ }^{[8]}$ The polysaccharide 'brushes' of the mucins are made up of carbohydrate chains between 5-15 monomer units in length, consisting predominantly of $\mathrm{N}$ - 
acetylgalactosamine, $\mathrm{N}$-acetylglucosamine, fucose, galactose, $\mathrm{N}$-acetylneuraminic acid and traces of mannose. The intermolecular interpenetration of these polysaccharide brushes, in combination with non-transient interactions of the cysteine-rich regions, is essential for the maintenance of the gel matrix. ${ }^{[8,9]}$

When speaking in terms of biomaterials science, mucoadhesion is defined as the adherence of a synthetic or natural polymer to a mucosal membrane via physical or chemical interactions. ${ }^{[10]}$ Mucoadhesive materials are widely used to develop dosage forms for transmucosal drug delivery via ocular, nasal, esophageal, oral, vaginal, rectal and intravesical routes of administration. ${ }^{[11-16]}$ The advantages offered by mucoadhesive formulations include the ease of dosage form administration, possibility of therapy termination (e.g. mucoadhesive tablets in the mouth), improved drug bioavailability, possibility of targeting particular organs (e.g. nasal route of administration provides access to central nervous system), etc. In addition to drug delivery, mucoadhesive materials are finding applications in food industry. ${ }^{[17,18]}$ Many theories pertaining to the predominant mechanisms of mucoadhesion have been proposed (Table 1). The mechanisms of adhesion to mucosa could be different and dependent on the nature of a dosage form. For example, solid dosage forms (such as tablets) will be affected by the process of hydration, whereas adhesion of liquid formulations will be more influenced by their rheological properties. The main focus of this manuscript will be the interactions best described by adsorption theory, specifically mucoadhesion occurring as a consequence of primary bonding' (i.e. covalent and ionic bonds). ${ }^{[10]}$ Furthermore this review will highlight some of the most prominent synthetic methodologies employed to modify polymeric materials in order to improve mucoadhesive properties. 
Table 1. Theories of mucoadhesion ${ }^{[10,11,19]}$

\begin{tabular}{|c|c|}
\hline $\begin{array}{c}\text { Theory of } \\
\text { mucoadhesion }\end{array}$ & Applicability of the theory and main mechanisms involved \\
\hline Electronic & $\begin{array}{l}\text { This theory considers a transfer of electrons between the dosage form and } \\
\text { mucosal surface, which leads to formation of electrical double layer at } \\
\text { the interface, resulting in electrostatic attraction. }\end{array}$ \\
\hline Absorption & $\begin{array}{l}\text { This theory relates mucoadhesion to formation of either weak physical } \\
\text { bonds (hydrogen bonding, van der Waals forces) or/and strong covalent } \\
\text { bonds between the material of a dosage form and mucins. }\end{array}$ \\
\hline Wetting & $\begin{array}{l}\text { Mostly applicable to liquid dosage forms. The theory considers the ability } \\
\text { of a dosage form to spread on mucosal surface, which is associated with } \\
\text { stronger mucoadhesive properties }\end{array}$ \\
\hline Diffusion & $\begin{array}{l}\text { This theory looks at penetration of macromolecules present in a dosage } \\
\text { form into the mucus gel and formation of an interpenetrating layer. This } \\
\text { penetration will be affected by the molecular weight of mucoadhesive } \\
\text { and flexibility of macromolecules. }\end{array}$ \\
\hline Fracture & $\begin{array}{l}\text { This theory relates the forces required for the separation of a dosage form } \\
\text { from mucosa after adhesion bond is formed }\end{array}$ \\
\hline Mechanical & $\begin{array}{l}\text { Adhesion results from interlocking of a liquid dosage form into } \\
\text { irregularities on a rough mucosal surface }\end{array}$ \\
\hline
\end{tabular}




\section{First generation (non-specific) primary bonding mucoadhesive materials}

\section{Cationic materials}

As a consequence of the anionic nature of mucin glycoproteins, the exploitation of potential electrostatic interactions with cationic materials was cited as one of the earliest primary bonding methods employed in designing new mucoadhesive systems. ${ }^{[20]}$ Owing to its biodegradability, biocompatibility and inherent cationic nature, chitosan, a semi-synthetic polyaminosaccharide, has been the most highly exploited of the first generation mucoadhesive materials. ${ }^{[21-23]}$

Chitin

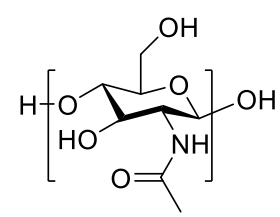

Chitosan

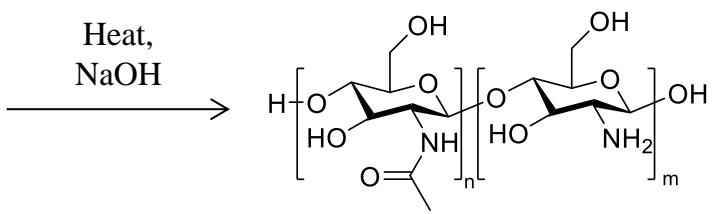

Figure 3. Deacetylation of chitin to yield chitosan.

Widely commercially available, chitosan is obtained through the deacetylation of the naturally occurring chitin, yielding, at varying degrees, free amine groups along the polysaccharide backbone (Figure 3). Owing to the $\mathrm{pK}_{\mathrm{a}}$ of these free amine groups $(\sim 6.3)$, chitosan is only soluble in acidic solutions $(\mathrm{pH}<6.0)$ when the amines become protonated, producing a cationic polyelectrolyte. This, in combination with hydrophobic and H-bonding interactions, allows for chitosan to effectively and non-specifically bind to the mucosal surface. ${ }^{[24]}$ In order to assess its viability as a potential pharmaceutical excipient, chitosan has been formulated into nanoparticles, microspheres, liposomes, capsules, fibres, beads, films, freeze-dried wafers, gels and tablets. ${ }^{[25-32]}$ Furthermore, chitosan has been modified with a plethora of mucoadhesivityenhancing moieties ${ }^{[33]}$, some of which will be discussed later. Recently, some attempts were reported to develop aminated cellulose as an alternative to chitosan. Jelkmann et $a l^{[34]}$ 
established that novel aminated cellulose derivative exhibits better mucoadhesive performance than chitosan. Similarly, poly(L-lysine) (PLL), is a naturally derived polyamine containing synthetic peptide, which also exhibits good mucoadhesive properties owing to its cationic nature. ${ }^{[20,35-37]}$ However PLL has been utilised far less than chitosan in pharmaceutical sciences owing to processing/formulation difficulties and relatively poor commercial availability. In addition to natural amino bearing polymers, synthetic non-degradable polymers poly(allylamine) hydrochloride (PAH) and poly((2-dimethylamino)ethyl methacrylate) (PDMAEMA) have also been investigated for their mucoadhesive capabilities. Both PAH and PDMAEMA are synthesised via radical polymerisation techniques (e.g. vinyl addition, free radical or controlled radical polymerisation), employing the commercially available allyl amine and 2-(dimethylamino)ethyl methacrylate monomers, respectively. Akin to chitosan, these synthetic materials were found to exhibit enhanced mucoadhesive properties in acidic environments owing to protonation of the amine derivatives. ${ }^{[38,39]}$ Furthermore these materials can be easily formulated into nanogels, liposomes and films, however, in the case of PAH, toxicity issues have restricted its application somewhat. ${ }^{[40]}$ Some other synthetic copolymers based on [2-(methacryloyloxy)ethyl]trimethylammonium chloride were also reported to exhibit mucoadhesive properties. ${ }^{[41]}$ 
First generation

mucoadhesive materials

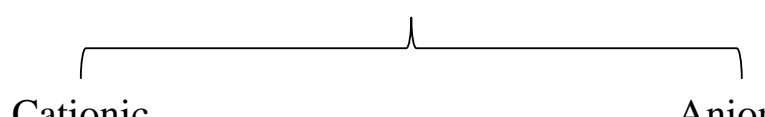

Cationic

(a)

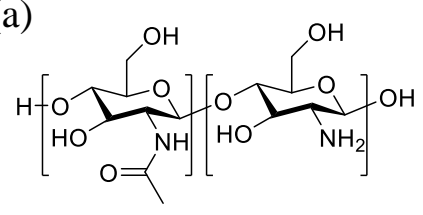

(b)

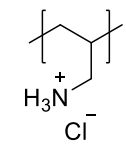

(c)

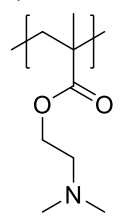

Anionic

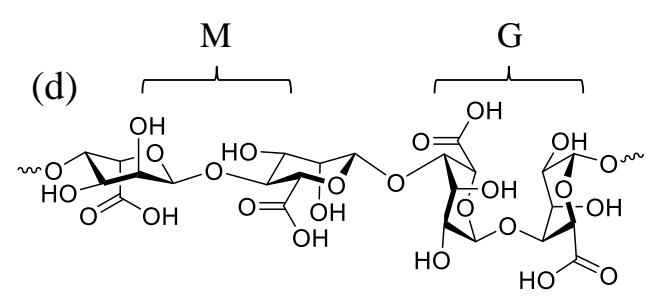

(e)

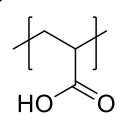

(f)

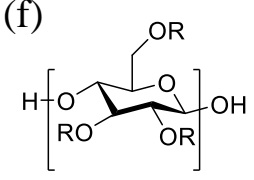

Figure 4. Examples of common first generation mucoadhesive materials. Cationic; (a) Chitosan, deacetylated to varying degrees, (b) poly(allylamine) hydrochloride and (c) PDMAEMA. Anionic; (d) Alginate, (e) poly(acrylic acid) and (f) carboxymethyl cellulose, R $=\mathrm{H}$ or $\mathrm{CH}_{2} \mathrm{COOH}$.

\section{Anionic materials}

Counterintuitively, as a consequence of their incompatible charges, anionic polymers have also been employed as first generation mucoadhesive excipients. ${ }^{[42]}$ There are comprehensive debates within the literature discussing the mechanism of adherence, with a large degree of ambiguity around the effect of and optimal $\mathrm{pH}$ ranges required to allow for adhesion of anionic materials. ${ }^{[14,43-45]}$ Like first generation cationic materials, naturally derived anionic polymers such as alginate, carboxymethyl cellulose (CMC) and, to a lesser degree, pectin have been widely used as mucoadhesive excipients owing to their carboxylic acid side groups (Figure 4). ${ }^{[46-50]}$ However, the most dominant material in the area of anionic mucoadhesives in recent years has been the commercially available synthetic polymer; poly(acrylic acid) (PAA). ${ }^{[51]}$ PAA is synthesised via free or controlled radical polymerisation of acrylic acid. As with 
alginate and $\mathrm{CMC}$, PAA has been formulated into gels and micro-/nano-carriers by complexation to bivalent cations such as calcium (II), however, the most studied PAA-based crosslinked networks in pharmaceutical literature has been Carbopol®. ${ }^{[52-54]}$ Carbopol ${ }^{\circledR}$ consists of PAA networks crosslinked with either allyl pentaerythritol or allyl sucrose, with varying degrees of crosslinking, molecular weights and viscosities available. These PAA-based materials have been used to prepare liposomes, coated particles, gels and micro- and nanoparticles through various formulation techniques, yielding materials with vastly enhanced mucoadhesive properties. ${ }^{[55-59]}$

\section{Second generation (specific) primary bonding mucoadhesive materials}

\section{Thiolated materials}

Arguably the most prolific of the second generation mucoadhesive materials in pharmaceutical science to date, pioneered largely by Bernkop-Schnürch et al., are thiol bearing materials referred to as 'thiomers'. ${ }^{\text {[60-62] }}$ The conjugation of free thiols onto a polymer backbone allows for increased mucoadhesive capabilities through disulphide bond formation with cysteine residues present at the surface of the mucosa. ${ }^{[62]}$ Formation of disulphide bonds between thiolated polymers and mucins was confirmed through a series of experiments involving the mucolytic agent cysteine, whose addition results in reduction of mucoadhesive bonding, and also through polymer/mucus diffusion studies. Traditionally, thiomers are generated via the immobilisation of sulfhydryl-functional moieties onto previously-known first generation mucoadhesive excipients in order to further enhance their mucoadhesive capabilities. ${ }^{[63]}$ As such, these first generation analogues can be broken into two subcategories; cationic and anionic thiomers, although their sulfhydryl immobilisation routes are almost identical. Two common methodologies for the conjugation of sulfhydryl containing compounds to both cationic and anionic excipients are (1) carbodiimide coupling between amines and carboxylic 
acids (Figure 5(c)) and (2) periodate treatment of polysaccharides (i.e. chitosan, alginate etc.) followed by reductive amination of a cysteamine Schiff-base adducts (Figure 5(a)). ${ }^{[64-66]}$ Additionally, the amine initiated ring-opening of 2-iminothiolane has been utilised to yield cationic thiomers (Figure 5(b)). ${ }^{[67,68]}$ Explicably, the most prevalent cationic thiomers are based on a chitosan backbone, however, cationic thiomers of hydroxyethylcellulose, poly(allylamine) and PDMAEMA derivatives have been synthesised. ${ }^{[69-72]}$ Conversely, poly(acrylic acid) and polycarbophil dominate the anionic thiomer field, although alginate, $\mathrm{CMC}$ and hyaluronic acid-based backbones have also been explored. ${ }^{[73-76]}$

\section{Cationic thiomers}

(a)

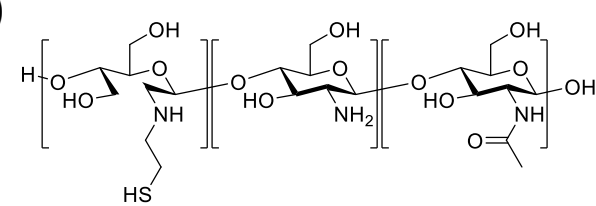

(b)

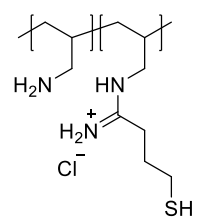

Anionic thiomers

(c)

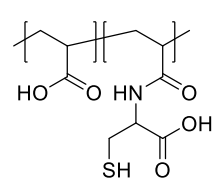

(d)

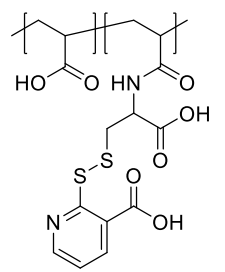

Figure 5. Examples of thiomers. Cationic; (a) thiol-bearing chitosan, (b) thiol-bearing poly(allyl amine). Anionic; (c) thiol-bearing PAA, (d) preactivated thiol-bearing PAA.

As a consequence of rapid thiol oxidation in aqueous solutions of $\mathrm{pH} \geq 5$, a second generation of thiomer known as 'preactivated' thiomers were designed in order to enhance the stability and mucoadhesive properties of first generation thiomers. Utilising previously known covalent chromatography techniques, thiomers containing pyridyl disulphide protecting groups were synthesised via disulphide exchange to yield preactivated thiomers which exhibit quantitative reactivity whilst being stable to oxidation. ${ }^{[77,78]}$ However, owing to the toxic nature of the 
pyridyl leaving group, 2-mercapto-nicotinaminde (2-MNA), a derivative of vitamin B3, was employed as a protecting group, yielding non-toxic preactivated thiomers (Figure 5(d)).

In an attempt to achieve materials with high incorporation of preactivated thiols, BernkopSchnürch et al. synthesised the novel preactivated thiol-containing monomer 6-(2acryloylamino-ethyldisulfanyl)-nicotinic acid (ACENA)(Figure 6(a)). This was subsequently copolymerised with acrylic acid to yield preactivated anionic thiomers which exhibited excellent cell viability and mucopenetrative properties. ${ }^{[79]}$ Other than ACENA, only one other bottom-up approach has been reported in the synthesis of novel thiomers. Cook et al. synthesised nanogels comprising of crosslinked poly(2-hydroxyethylmethacrylate-co-2(acetylthio)ethylacrylate) (P(HEMA-co-ATEA)) copolymers, which were subsequently treated with sodium thiomethoxide to yield thiol-bearing mucoadhesive nanogels. ${ }^{[80]}$

(a)

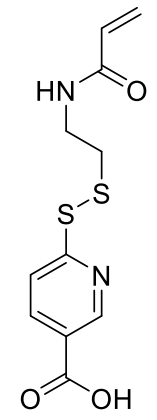

(b)

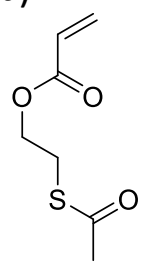

Figure 6. Examples of monomers with protected thiol groups; (a) 6-(2-acryloylaminoethyldisulfanyl)-nicotinic acid (ACENA) and (b) 2-(acetylthio)ethylacrylate (ATEA).

\section{Catechol-bearing materials}

Since being first identified in the mussel adhesive proteins (MAPs) of marine mussels by Waite et al. in the 1980's, catechol-bearing materials have been of increasingly high interest in the field of wet-resistant adhesives as a consequence of their ability to adhere to a wide-range 
organic and inorganic surfaces. ${ }^{[81,82]}$ Although there have been pronounced advancements in the introduction of catechols (i.e. dopamine, hydrocaffeic acid, pyrocatechol etc.)(Figure 7) as adhesive-enhancing moieties through chemical modification of natural and synthetic polymers, the application of these materials as mucoadhesives has been somewhat limited to the enhancement of the mucoadhesive properties of chitosan/chitin (Cat-Chit). As mentioned previously, upon deacetylation, chitosan exhibits enhanced mucoadhesive properties owed to electrostatic interactions with the cationic chitosan and the negatively charged mucosa. Similarly, another important contributor of adhesive properties of MAPs is the presence of positively charged lysine and histidine residues; therefore chitosan offers a convenient cationic backbone analogous to the MAP amino acid composition. ${ }^{[81]}$ The cationic nature of the CatChit formulations allows for transient mucoadhesion via electrostatic interactions before consolidation through catechol-mediated covalent bond formation. These covalent interactions occur as a consequence of $o$-quinone formation under physiological conditions through partial deprotonation of the catechols and subsequent reaction with amine and thiol residues present on the mucosal surface. ${ }^{[83-86]}$

(a)<smiles>Oc1ccccc1O</smiles>

(b)<smiles>O=Cc1ccc(O)c(O)c1</smiles>

(c)<smiles>NCCc1ccc(O)c(O)c1</smiles>

(d)<smiles>O=C(O)CCc1ccc(O)c(O)c1</smiles><smiles>N[C@@H](Cc1ccc(O)c(O)c1)C(=O)O</smiles>

Figure 7. Examples of catechol-containing molecules used to modify polymer backbones; (a) pyrocatechol, (b) 3,4-dihydroxy benzaldehyde, (c) dopamine, (d) hydrocaffeic acid and (e) LDOPA. 


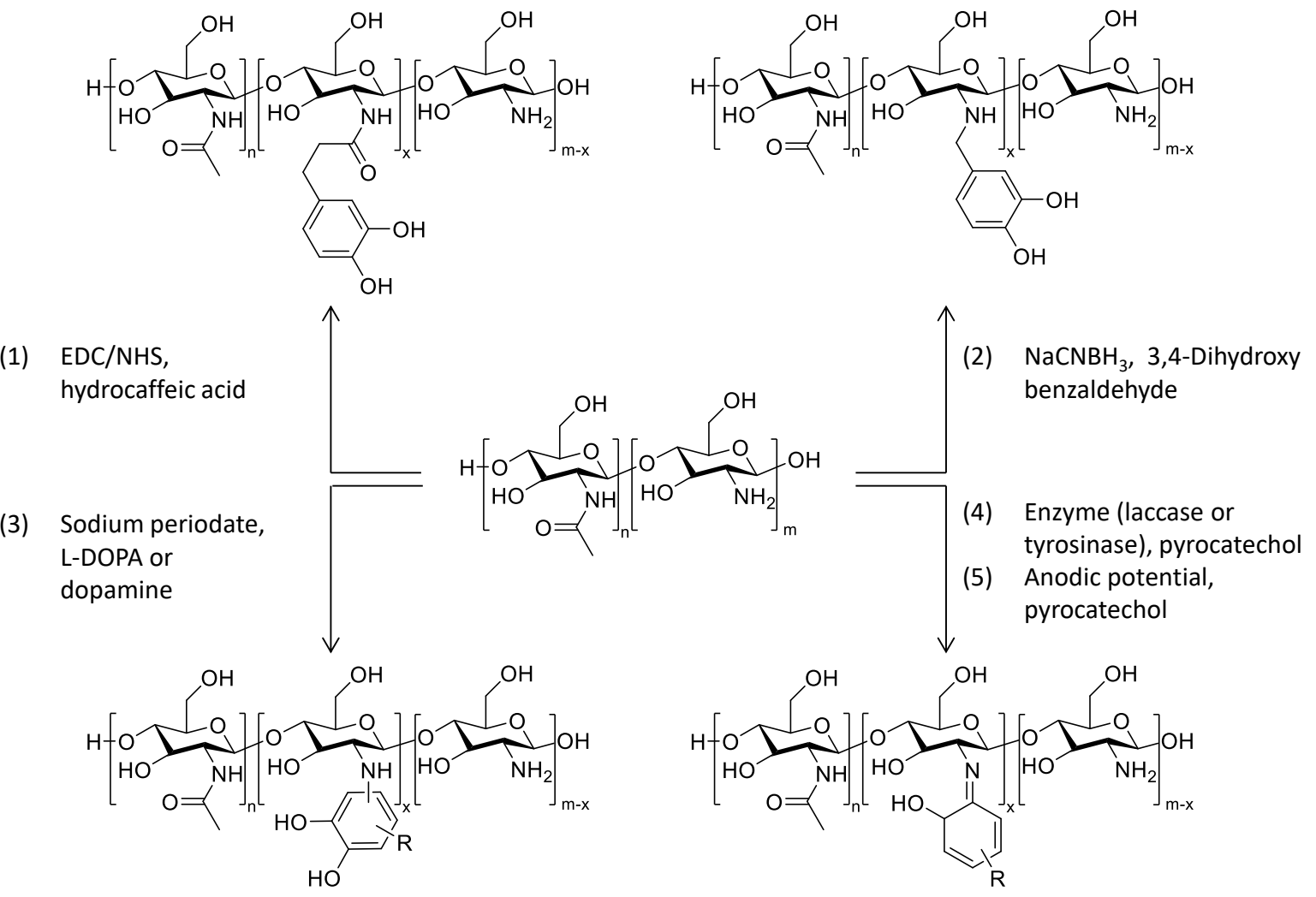

Figure 8. Synthetic routes to catechol-functionalised chitosan. Where EDC and NHS are $N$-(3diethylaminopropyl)- $N$ '-ethylcarbodiimide and $N$-hydroxysuccinimide, respectively.

Classically there are 5 synthetic routes to yield catechol functionalised chitosan, these are; (1) amide bond formation through carbodiimide coupling chemistries utilising carboxylic acid containing catechols (i.e. hydrocaffeic acid), (2) reductive amination of aldehyde containing catechols with sodium cyanoborohydride, (3) direct coupling utilising oxidants such as sodium periodate to yield catechol-amine adducts, (4) enzymatic synthesis utilising tyrosinase or laccase-mediated $o$-quinone formation and subsequent reaction with chitosan yielding Schiff base adducts and (5) electrochemical synthesis via o-quinone formation, through the application of an anodic potential, and subsequent reaction with electro-deposited chitosan yielding Schiff-base adducts (Figure 8$).{ }^{[87,88]}$ Of these synthetic strategies, carbodiimide- 
mediated amide formation and reductive amination offer the highest degree of catechol conjugation (> $80 \mathrm{~mol} \%)$, although the latter offered significantly faster reaction times.

\section{Boronate-bearing materials}

Owing to their ability to complex with 1,2-cis-diols, boronic acid derivatives, such as phenylboronic acid (PBA), have been cited as interesting prospective functionalities for enhancing mucoadhesive properties through interactions with saccharide residues present at the mucosa surface. ${ }^{[89]}$ In order for the formation of cyclic boronic esters with 1,2-cis-diols, it is generally accepted that PBAs must be in their anionic form. However, as a consequence their weak acidic nature $\left(\mathrm{pK}_{\mathrm{a}} \sim 7-9\right)$, substituted PBA's tend to only form boronic esters with monosaccharides under alkaline conditions uncommon to mucosa. ${ }^{[90,91]}$ An important exception to this is $\mathrm{N}$-acetylneraminic acid (sialic acid), present in mucin glycoproteins, which can bind to PBAs under neutral and acidic ( pH 4) conditions, more common to physiological conditions of the mucosa (Figure 9). ${ }^{[92,93]}$ Owing to this unique capability, PBA containing polymers have also been utilised in detection of sialic acid expression in cancer metastasis, cell labelling and biosensor development. ${ }^{[94-97]}$

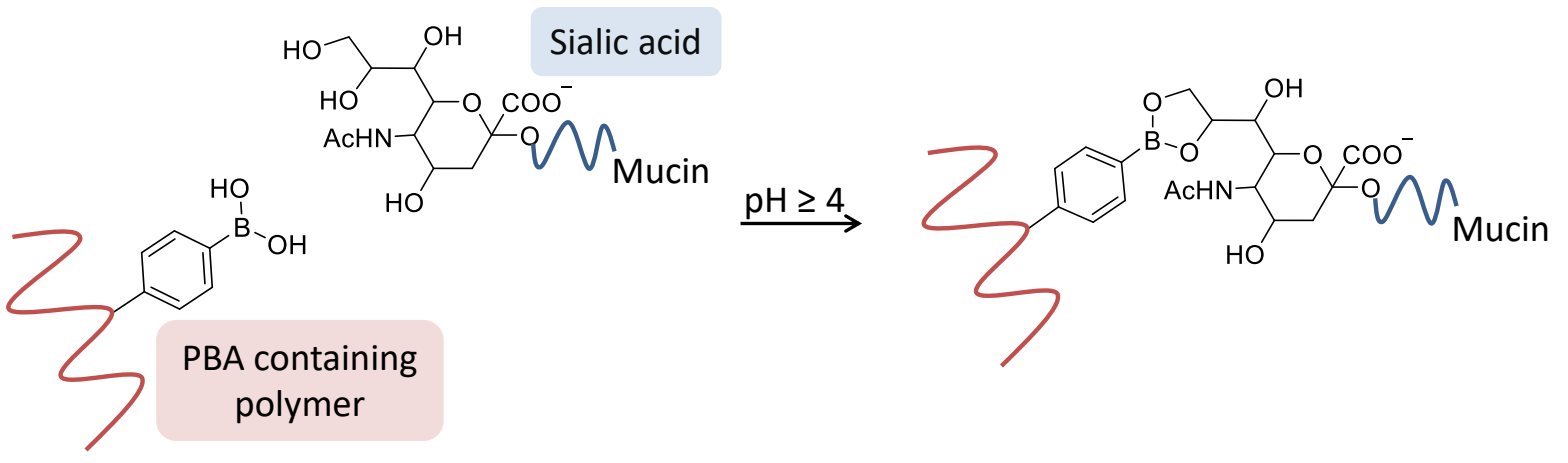

Figure 9. Schematic of phenylboronic acid-containing materials covalently binding to sialic acid residues present in mucin glycoproteins.

In an analogous methodology to the catechol functionalisation of chitosan, phenylboronic acid derivatives (e.g. 4-formylphenylboronic acid and 4-aminophenylboronic acid) have been 
grafted to polymer scaffolds through reductive amination and carbodiimide mediated coupling chemistry with reasonably high degrees of conjugation. ${ }^{[92,98]}$ Most recently, Kolawole et al ${ }^{[99]}$ reported the synthesis of boronated chitosan by the reaction with 4-carboxyphenylboronic acid mediated with $N$-3(dimethylaminopropyl)- $N$-ethylcarbodiimide hydrochloride and $N$ hydroxysuccinimide and demonstrated excellent mucoadhesive properties of these derivatives.

However, more prevalently in recent times, PBAs with polymerisable functionalities such as cyclic carbonates, vinylic and acrylamide side groups, have been employed to yield materials with high PBA content while allowing for greater control over molecular weight, polymer morphology and higher architectures (Figure 10). ${ }^{[100-102]}$ Arguably, of these PBA containing monomers, 3-(acrylamido)phenylboronic acid (AAPB) has received the greatest degree of attention as a consequence of its facile synthesis/commercial availability and several robust polymerisation routes, namely free radical polymerisation, reversible addition-fragmentation chain transfer (RAFT) polymerisation and atom-transfer radical polymerisation (ATRP).

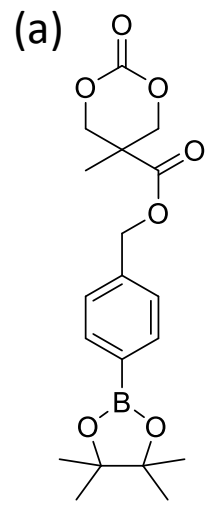

(b)

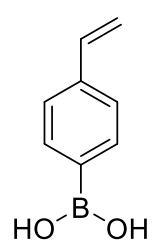

(c)<smiles>C=CC(=O)Nc1ccc(B(O)O)cc1</smiles>

Figure 10. Examples of phenylboronic acid-containing monomers; (a) phenylboronic acid functional cyclic carbonate (b) 4-vinylphenylboronic acid and (c) 3(acrylamido)phenylboronic acid. 
Prosperi-Porta et al. developed a series of poly(L-lactide)- $b$-poly(methacrylic acid-co-3acrylamidophenylboronic acid) micelles, via RAFT polymerisation, for application as mucoadhesive drug delivery vehicles to the ocular mucosa. Prosperi-Porta et al. demonstrated that PBA-containing micelles exhibited enhanced mucoadhesive capabilities when compared to chitosan and offered a viable route to improved ocular delivery of cyclosporine A. Furthermore, the in vitro cell viability showed no significant cytotoxicity in conjunction with minimal in vivo ocular irritation rat model. ${ }^{[103]}$

\section{Acrylated and methacrylated materials}

First proposed by Davidovich-Pinhas and Bianco-Peled, acrylated polymers were highlighted as a novel class of mucoadhesive materials owing to their ability to covalently bind with cysteine residues, present in mucin glycoproteins, via a Michael-type addition reaction. ${ }^{[104]}$ To date, only a few examples of acrylated mucoadhesive materials have been reported, which have been obtained via a grafting to approach. The first example of an acrylated mucoadhesive polymer was poly(ethylene glycol) diacrylate (PEG-DA), reported by Davidovich-Pinhas and Bianco-Peled (Figure 11). ${ }^{[105]}$

(a)

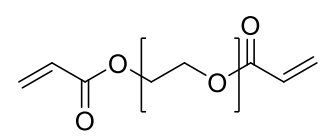

(b)<smiles>C=CC(=O)OCC(=O)OC(C)COCC(C)OC(=O)C=C</smiles>

(c)

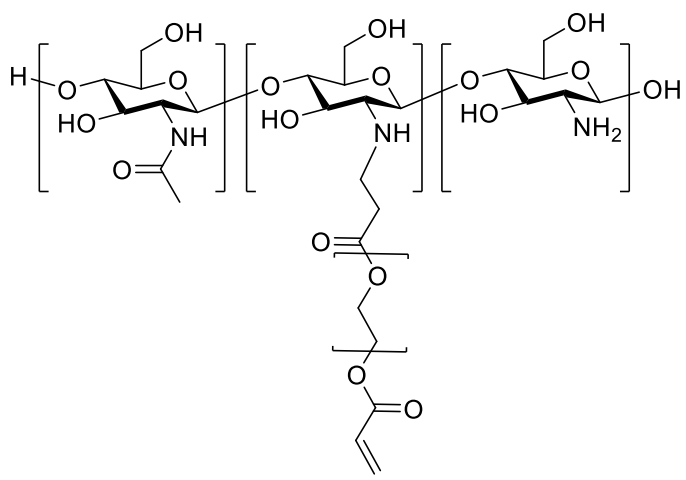

(d)

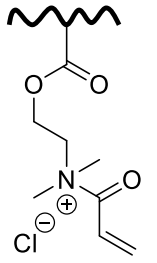

Figure 11. Examples of acrylated polymers; (a) PEG diacrylate, (b) Pluronic F127 diacrylate, (c) chitosan PEG acrylate and (d) acryloyl quaternized PDMAEMA. 
The acrylation of PEG was achieved by reaction of the PEG terminal hydroxyl groups with acryloyl chloride under basic conditions. This same methodology was used to modify Pluronic F127, yielding thermoresponsive acrylated micelles which could subsequently as drug delivery devices for hydrophobic drugs. ${ }^{[106]}$ In order it enhance the mucoadhesive capabilities of cationic PDMAEMA nanogels, Brannigan et al. quaternized the tertiary amine of the DMAEMA repeat units with acryloyl chloride, yielding highly mucoadhesive nanogels which were capable of encapsulating and releasing therapeutic compounds for the ocular drug delivery. ${ }^{[107]}$ Most recently, Porfiryeva et al ${ }^{[108]}$ used similar reaction for acrylation of Eudragit EPO, a terpolymer based on N,N-dimethylaminoethyl methacrylate with methylmethacrylate and butylmethacrylate. This material is manufactured by Evonik Industries AG and is approved as a pharmaceutical excipient. Acryloylation of Eudragit EPO significantly improved its mucoadhesive properties, which was demonstrated fluorescent flow-through technique with sheep nasal mucosa. Using slug mucosal irritation assay it was demonstrated that acrylated Eudragit EPO is a non-irritant material, whose biocompatible properties are similar to the parent polymer.

Acrylated chitosan was also synthesised by Shitrit et al ${ }^{[109]}$ by reacting an excess of PEG-DA with free amine groups via a Michael-type reaction. These modified chitosan-based materials were found to have enhanced mucoadhesive properties when adhered to porcine intestinal tissues.

Polymers modified with methacrylate groups also exhibit enhanced mucoadhesive properties similarly to acrylated materials. Kolawole et al ${ }^{[110]}$ reported the synthesis of methacrylated chitosan with two degrees of substitution using its reaction with methacrylic anhydride. The retention of sodium fluorescein formulated with methacrylated chitosans was evaluated using flow-through technique with porcine bladder mucosa in vitro. It was established that methacrylated chitosan with greater degree of methacrylation $(38.5 \pm 3.9 \%)$ exhibited superior 
mucoadhesive performance compared to unmodified polysaccharide. The toxicological evaluation of methacrylated chitosans using UMUC3 cell viability studies indicated that methacrylation did not result in any unwanted reduction in material biocompatibility.

\section{Maleimide-functionalised materials}

One of the most recent advancements in the synthesis of mucoadhesive materials is the exploitation of the well-known maleimide-thiol 'click-like' reaction. Akin to thiomers and acrylated materials, maleimide-bearing materials covalently bind to the free thiols groups of cysteine residues present in mucin glycoproteins. First reported by the Khutoryanskiy group, ${ }^{93}$ only a few examples are present in the literature to date of maleimide-bearing materials being used as mucoadhesive excipients. In the first instance, a protected maleimide acrylate monomer was synthesised and subsequently co-polymerised with $N$-vinyl pyrrolidone (NVP) via freeradical emulsion polymerisation and deprotected to yield maleimide-bearing nanogels (Figure 12(a)). ${ }^{[11]}$ These nano-materials exhibited superior mucoadhesive capabilities than first generation mucoadhesives when applied to bovine conjunctive tissue. Furthermore, the nanogels were loaded with a model therapeutic agent and were found to be viable drug delivery devices, following first order release kinetics. 
(a)

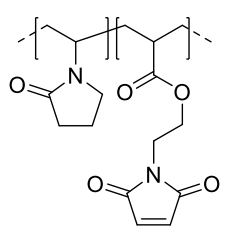

(c)

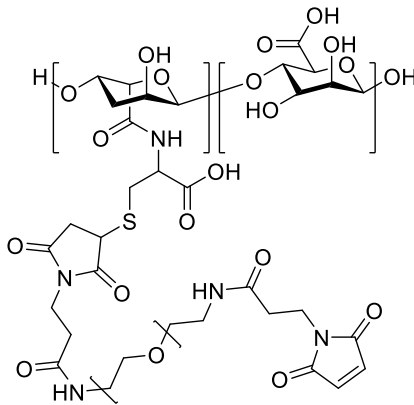

(b)

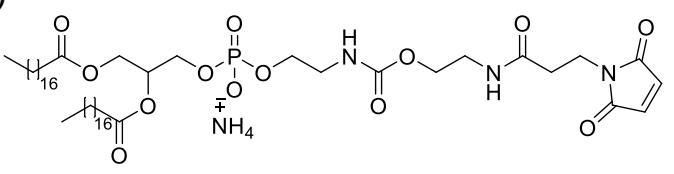

(d)

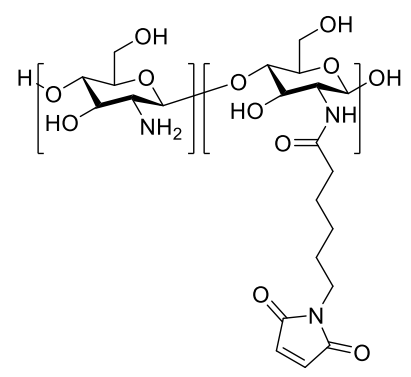

Figure 12. Maleimide-bearing mucoadhesive materials; (a) copolymer of NVP and deprotected maleimide acrylate, (b) lipidyl PEG-maleimide, (c) PEG maleimide-grafted alginate and (d) 6-maleimidohexanoic acid-grafted chitosan.

In addition, Bianco-Peled et al, synthesised maleimide functional alginate by reacting excess commercially available PEG-bis-maleimide with a pre-synthesised thiolated alginate (Figure 12 (b)). ${ }^{[112]}$ It was found that the PEG maleimide-bearing alginate (Alg-PEGM) exhibited a two-fold increase in mucoadhesive properties when compared to the thiomer analogue. Furthermore, Alg-PEGM exhibited excellent bio-compatibility and were found to be non-toxic to normal dermal human fibroblast (NDHF) cells. Most recently, Kaldybekov et al. yielded maleimide-bearing liposomes utilising the commercially available maleimide-functional PEGylated lipid, 1,2-distearoyl-sn-glycero-3-phosphoethanolamine- $N$ [maleimide(polyethylene glycol)-2000] ammonium salt (PEG2000-DSPE-Mal). ${ }^{[113]}$ These liposomes were used as mucoadhesive chemotherapeutic delivery vehicles to the urinary bladder. It was found that the maleimide-bearing liposomes exhibited a superior in vitro retention on bladder mucosa, relative to non-functional liposomes, owing to the formation of covalent bonds with thiols present in mucosal tissue. Additionally recently Sahatsapan et al ${ }^{[114]}$ 
reported the synthesis of 6-maleimidohexanoic acid-grafted chitosan (MHA-CHI) and its evaluation as a new mucoadhesive polymer in comparison with thiolated chitosan modified by conjugation with cysteine (Cys-CHI). Both derivatives of chitosan were formulated as tablets and their adhesion to porcine buccal membrane was studied using tensile test ex vivo. The mucoadhesive strength of tablets composed of MHA-CHI was significantly greater compared to Cys-CHI. Biocompatibility of MHA-CHI and CyS-CHI was also evaluated using MTT assay with normal human gingival fibroblast cells. It was established that both modified chitosans do not cause any toxicity reactions at polymer concentrations up to $1000 \mu \mathrm{g} / \mathrm{mL}$.

\section{$N$-hydroxy(sulfo)succinimide ester - functionalised materials}

A new class of polymers capable of binding to mucus components covalently was very recently introduced by Bernkop-Schnurch et $a l^{[115,116]}$; these materials could specifically target amino groups of lysine and arginine present in mucin glycoproteins. These polymers were synthesised by covalently conjugating $\mathrm{N}$-hydroxysuccinimide (NHS) or N-hydroxysulfosuccinimide (Sulfo-NHS) to PAA (Figure 13).

(a)

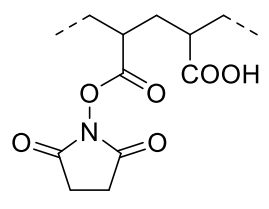

(b)

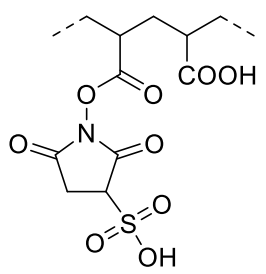

Figure 13. Conjugates of poly(acrylic acid) with (a) N-hydroxysuccinimide and (b) Nhydroxysulfosuccinimide. 
Solid compacts were prepared based on these modified polymers and their adhesion to freshly excised porcine intestinal mucosa was evaluated using both rotating disc and tensile methods. The superior mucoadhesive properties of Sulfo-NHS-PAA were demonstrated compared to the parent polymer and it was related to the possibility of forming amide bond with mucins under physiological conditions. Toxicological evaluation of Sulfo-NHS-PAA conjugates was conducted using hemolysis and Caco-2 cell assays. It was established that these materials did not show any haemolytic properties, except for $0.5 \%$ solution of Sulfo-NHS-PAA containing $885.5 \mu \mathrm{mol} / \mathrm{g}$ sulfo-NHS-groups ${ }^{[116]}$. Sulfo-NHS-PAA conjugates also did not cause any toxicological effects on Caco-2 cells and exhibited better cytotoxicity profiles compared to PAA-cystein conjugates, which are considered as generally safe for mucosal applications.

\section{Comparison of different strategies to enhance mucoadhesion}

Different strategies to enhance mucoadhesive properties of conventional polymers have been considered in this review. Table 2 presents the comparison of these strategies and highlights the mechanisms of enhanced mucoadhesion, progress in development of these materials as well as some advantages and disadvantages. So far, thiolated polymers are most widely researched as second generation mucoadhesives and there are already some examples of commercialised products. Other strategies to improve mucoadhesive performance of polymers have emerged only recently and have shown some advantages over polymeric thiomers. Further research will 
be needed into these systems to establish if these could also be used in the future for developing new medicines for transmucosal drug delivery.

Moreover, very little is currently known about the relative strength of adhesion for polymers prepared using different strategies. Further research is needed to establish some orders of adhesive strength for polymers modified with thiol, catechol, acrylate, methacrylate, maleimide, and N-hydroxy(sulfo)succinimide ester groups. A comparison of other physicochemical and biological characteristics between these classes of materials will also be useful, including their storage stability and biocompatibility.

\section{Table 2. Comparison of different strategies}

\begin{tabular}{|c|c|c|c|}
\hline $\begin{array}{l}\text { Mucoadhesive } \\
\text { enhancing } \\
\text { functionality }\end{array}$ & $\begin{array}{c}\text { Nature of } \\
\text { interactions } \\
\text { with mucins }\end{array}$ & $\begin{array}{l}\text { Progress in research } \\
\text { and development of } \\
\text { these materials }\end{array}$ & $\begin{array}{l}\text { Advantages and } \\
\text { disadvantages }\end{array}$ \\
\hline Thiol & $\begin{array}{l}\text { Disulphide bond } \\
\text { formation with } \\
\text { thiol groups in } \\
\text { mucins }\end{array}$ & $\begin{array}{l}>450 \text { publications. } \\
29 \text { patents } \\
\text { Commercially } \\
\text { available materials: } \\
\text { Lacrimera }{ }^{\circledR} \\
\text { (chitosan- } N \text { - } \\
\text { acetylcysteine } \\
\text { conjugate) }{ }^{[117]}\end{array}$ & $\begin{array}{l}\text { Thiols are prone to } \\
\text { oxidation, resulting in } \\
\text { unwanted cross-linking of } \\
\text { polymers }\end{array}$ \\
\hline Catechol & $\begin{array}{l}\text { Catechol-thiol } \\
\text { and catechol- } \\
\text { amine adducts } \\
\text { formation with } \\
\text { mucins }\end{array}$ & $\begin{array}{l}<20 \text { publications. } \\
4 \text { patents. } \\
\text { However, excellent } \\
\text { progress was made in } \\
\text { the synthesis of these }\end{array}$ & $\begin{array}{l}\text { Catechols are prone to } \\
\text { oxidation, which results in } \\
\text { changes in material colour } \\
\text { and possible reduction in } \\
\text { mucoadhesive properties }^{[88]}\end{array}$ \\
\hline
\end{tabular}




\begin{tabular}{|c|c|c|c|}
\hline & & $\begin{array}{l}\text { materials for other } \\
\text { applications }{ }^{[118]}\end{array}$ & \\
\hline Boronate & $\begin{array}{l}\text { Dynamic } \\
\text { covalent bond } \\
\text { with 1,2-cys- } \\
\text { diols in } \\
\text { carbohydrate } \\
\text { fragments of } \\
\text { mucins }\end{array}$ & $\begin{array}{l}<5 \text { publications. } \\
\text { However, excellent } \\
\text { progress was made in } \\
\text { the synthesis of these } \\
\text { materials for other } \\
\text { medical } \\
\text { applications }\end{array}$ & $\begin{array}{l}\text { Possible limitations imposed } \\
\text { by the conditions required } \\
\text { for boronate-sugar } \\
\text { interactions as the optimal } \\
\mathrm{pH} \text { needed is often above } \\
\text { physiological ranges }{ }^{[89]} \text { No } \\
\text { tendency for inter- and } \\
\text { intramolecular cross-linking }\end{array}$ \\
\hline $\begin{array}{l}\text { Acrylate and } \\
\text { methacrylate }\end{array}$ & $\begin{array}{l}\text { Michael-type } \\
\text { addition reaction } \\
\text { with thiol groups } \\
\text { in mucins }\end{array}$ & $<5$ publications. & $\begin{array}{l}\text { Potentially better storage } \\
\text { stability compared to } \\
\text { thiolated polymers. No } \\
\text { tendency for inter- and } \\
\text { intramolecular cross-linking }\end{array}$ \\
\hline Maleimide & $\begin{array}{l}\text { Maleimide-thiol } \\
\text { click reaction } \\
\text { with thiol groups } \\
\text { in mucins }\end{array}$ & $\begin{array}{l}<5 \text { publications } \\
1 \text { patent }\end{array}$ & $\begin{array}{l}\text { Potentially better storage } \\
\text { stability compared to } \\
\text { thiolated polymers. No } \\
\text { tendency for inter- and } \\
\text { intramolecular cross-linking }\end{array}$ \\
\hline $\begin{array}{l}\quad N- \\
\text { hydroxy(sulfo)s } \\
\text { uccinimide ester }\end{array}$ & $\begin{array}{l}\text { Reaction with } \\
\text { amino groups of } \\
\text { lysine and } \\
\text { arginine present } \\
\text { with mucins }\end{array}$ & $<5$ publications & $\begin{array}{l}\text { Adhesion to mucosal } \\
\text { surfaces is not reliant on } \\
\text { cysteine rich domains in } \\
\text { mucins. No tendency for } \\
\text { inter- and intramolecular } \\
\text { cross-linking }\end{array}$ \\
\hline
\end{tabular}

\section{Conclusions}

In conclusion, it is evident that the field of mucoadhesive materials has seen significant developments in recent times, predominantly as a consequence of advances in polymer chemistry and coupling techniques. From their inception mucoadhesive materials have 
progressed from conventional water-soluble, natural and semi-synthetic polymers to multifaceted functional materials with higher architectures. Several classes of polymers with enhanced mucoadhesive performance have emerged in the recent decade in addition to already established thiolated materials. These include polymers bearing catechol-, boronate-, acrylate, methacrylate-, maleimide- and N-hydroxy(sulfo)succinimide ester- groups. We believe that the future of mucoadhesive materials lies in the discovery and exploitation of mucoadhesive functionalities in the synthesis of novel polymers.

\section{Acknowledgements}

The authors would like to gratefully acknowledge the Leverhulme Trust for funding (RPG2013-017).

\section{References}

[1] C. Marriot, N. P. Gregory, "Mucus physiology and pathology", in Bioadhesive Drug Delivery Systems, V. Lanaerts and R. Gurny, Eds., CRC Press, Florida, 1990, p. 1.

[2] S. J. Coles, K. R. Bhaskar, D. D. O'Sullivan, K. H. Neill, L. M. Reid, "Airway Mucus: Composition and Regulation of its Secretion by Neuropeptides in vitro", in Ciba Foundation Symposium 109 - Mucus and Mucosa, John Wiley \& Sons, Ltd., 2008, p. 40.

[3] M. E. V. Johansson, D. Ambort, T. Pelaseyed, A. Schütte, J. K. Gustafsson, A. Ermund, D. B. Subramani, J. M. Holmén-Larsson, K. A. Thomsson, J. H. Bergström, S. van der Post, A. M. Rodriguez-Piñeiro, H. Sjövall, M. Bäckström, G. C. Hansson, Cellular and Molecular Life Sciences 2011, 68, 3635.

[4] R. A. Cone, Adv Drug Deliver Rev 2009, 61, 75.

[5] L. Serra, J. Doménech, N. A. Peppas, European Journal of Pharmaceutics and Biopharmaceutics 2009, 71, 519.

[6] S. K. Lai, Y.-Y. Wang, D. Wirtz, J. Hanes, Adv Drug Deliver Rev 2009, 61, 86.

[7] R. Bansil, B. S. Turner, Adv Drug Deliver Rev 2018, 124, 3.

[8] M. Berry, A. Corfield, "Structure and properties of mucins", in Mucoadhesive Materials and Drug Delivery Systems, V.V. Khutoryanskiy, Ed., John Wiley \& Sons, Ltd., 2014, p. 135.

[9] R. Bansil, B. S. Turner, Current Opinion in Colloid \& Interface Science 2006, 11, 164.

[10] J. D. Smart, Adv Drug Deliver Rev 2005, 57, 1556.

[11] V. V. Khutoryanskiy, Macromolecular Bioscience 2011, 11, 748.

[12] V. V. Khutoryanskiy, "Mucoadhesive materials and drug delivery systems", John Wiley \& Sons, 2014.

[13] A. Sosnik, J. das Neves, B. Sarmento, Progress in Polymer Science 2014, 39, 2030. 
[14] P. Schattling, E. Taipaleenmäki, Y. Zhang, B. Städler, Macromolecular Bioscience 2017, 17, 1700060.

[15] A. R. Mackie, F. M. Goycoolea, B. Menchicchi, C. M. Caramella, F. Saporito, S. Lee, K. Stephansen, I. S. Chronakis, M. Hiorth, M. Adamczak, M. Waldner, H. M. Nielsen, L. Marcelloni, Macromolecular Bioscience 2017, 17, 1600534.

[16] H. Batchelor, Pharm Res-Dordr 2005, 22, 175.

[17] S. L. Cook, S. Woods, L. Methven, J. K. Parker, V. V. Khutoryanskiy, Food Chemistry 2018, 240, 482.

[18] S. L. Cook, S. P. Bull, L. Methven, J. K. Parker, V. V. Khutoryanskiy, Food Hydrocolloids 2017, 72, 281.

[19] J. D. Smart, "Theories of mucoadhesion", in Mucoadhesive materials and drug delivery systems, V.V. Khutoryanskiy, Ed., John Wiley \& Sons, Chichester, 2014, p. 159.

[20] J. D. Schulz, M. A. Gauthier, J.-C. Leroux, European Journal of Pharmaceutics and Biopharmaceutics 2015, 97, 427.

[21] A. Bernkop-Schnürch, S. Dünnhaupt, European Journal of Pharmaceutics and Biopharmaceutics 2012, 81, 463.

[22] M. Dash, F. Chiellini, R. M. Ottenbrite, E. Chiellini, Progress in Polymer Science 2011, 36,981 .

[23] J. Boateng, I. Ayensu, H. Pawar, "Chitosan", in Mucoadhesive Materials and Drug Delivery Systems, John Wiley \& Sons, Ltd, 2014, p. 233.

[24] V. Zargar, M. Asghari, A. Dashti, ChemBioEng Reviews 2015, 2, 204.

[25] M. T. Cook, T. Saratoon, G. Tzortzis, A. Edwards, D. Charalampopoulos, V. V. Khutoryanskiy, Biomacromolecules 2013, 14, 387.

[26] I. A. Sogias, A. C. Williams, V. V. Khutoryanskiy, Int J Pharmaceut 2012, 436, 602.

[27] X. Qu, V. V. Khutoryanskiy, A. Stewart, S. Rahman, B. Papahadjopoulos-Sternberg, C. Dufes, D. McCarthy, C. G. Wilson, R. Lyons, K. C. Carter, A. Schätzlein, I. F. Uchegbu, Biomacromolecules 2006, 7, 3452.

[28] V. Dodane, V. D. Vilivalam, Pharmaceutical Science \& Technology Today 1998, 1, 246.

[29] R. Ghaffarian, E. P. Herrero, H. Oh, S. R. Raghavan, S. Muro, Advanced functional materials 2016, 26, 3382.

[30] C.-M. Lehr, J. A. Bouwstra, E. H. Schacht, H. E. Junginger, Int J Pharmaceut 1992, 78, 43.

[31] I. Ayensu, J. C. Mitchell, J. S. Boateng, Colloid Surface B 2012, 91, 258.

[32] J. S. Boateng, A. D. Auffret, K. H. Matthews, M. J. Humphrey, H. N. E. Stevens, G. M. Eccleston, Int J Pharmaceut 2010, 389, 24.

[33] T. M. M. Ways, W. M. Lau, V. V. Khutoryanskiy, Polymers-Basel 2018, 10.

[34] M. Jelkmann, C. Menzel, R. A. Baus, P. Ausserhofer, D. Baecker, R. Gust, A. BernkopSchnurch, Biomacromolecules 2018, 19, 4059.

[35] P. Calvo, J. L. Vila-Jato, M. a. J. Alonso, Int J Pharmaceut 1997, 153, 41.

[36] H. Guo, W. Xu, J. Chen, L. Yan, J. Ding, Y. Hou, X. Chen, Journal of Controlled Release 2017, 259, 136.

[37] M. A. Islam, P. Bajracharya, S.-K. Kang, C.-H. Yun, E.-M. Kim, H.-J. Jeong, Y.-J. Choi, E.-B. Kim, C.-S. Cho, Journal of Nanoscience and Nanotechnology 2011, 11, 7091.

[38] N. Nikogeorgos, N. J. Patil, B. Zappone, S. Lee, Polymer 2016, 100, 158.

[39] S. Keely, A. Rullay, C. Wilson, A. Carmichael, S. Carrington, A. Corfield, D. M. Haddleton, D. J. Brayden, Pharm Res-Dordr 2005, 22, 38.

[40] C. J. Thompson, L. Tetley, I. F. Uchegbu, W. P. Cheng, Int J Pharmaceut 2009, 376, 46. [41] N. A. Fefelova, Z. S. Nurkeeva, G. A. Mun, V. V. Khutoryanskiy, Int J Pharmaceut 2007, $339,25$. 
[42] S.-H. S. Leung, J. R. Robinson, "Polyanionic Polymers in Bio- and Mucoadhesive Drug Delivery", in Polyelectrolyte Gels, American Chemical Society, 1992, p. 269.

[43] S. A. Mortazavi, B. G. Carpenter, J. D. Smart, Int J Pharmaceut 1993, 94, 195.

[44] F. Madsen, K. Eberth, J. D. Smart, Journal of Controlled Release 1998, 50, 167.

[45] R. G. Riley, J. D. Smart, J. Tsibouklis, P. W. Dettmar, F. Hampson, J. A. Davis, G. Kelly, W. R. Wilber, Int J Pharmaceut 2001, 217, 87.

[46] W. J. Cho, S. H. Oh, J. H. Lee, Journal of Biomaterials Science, Polymer Edition 2010, 21,701 .

[47] A. O. Adebisi, P. R. Laity, B. R. Conway, Journal of Pharmacy and Pharmacology 2015, $67,511$.

[48] S. Rossi, M. C. Bonferoni, F. Ferrari, C. Caramella, Pharmaceutical Development and Technology 1999, 4, 55.

[49] F. Brako, B. Raimi-Abraham, S. Mahalingam, D. Q. M. Craig, M. Edirisinghe, European Polymer Journal 2015, 70, 186.

[50] E. Hagesaether, S. A. Sande, Drug Development and Industrial Pharmacy 2007, 33, 417.

[51] H. Park, J. R. Robinson, Pharm Res-Dordr 1987, 4, 457.

[52] V. Grabovac, D. Guggi, A. Bernkop-Schnürch, Adv Drug Deliver Rev 2005, 57, 1713.

[53] J. S. Chu, R. Chandrasekharan, G. L. Amidon, N. D. Weiner, A. H. Goldberg, Pharm ResDordr 1991, 8, 1408.

[54] G. Bonacucina, S. Martelli, G. F. Palmieri, Int J Pharmaceut 2004, 282, 115.

[55] P. Sriamornsak, J. Thongborisute, H. Takeuchi, "Liposome-Based Mucoadhesive Formulations for Oral Delivery of Macromolecules", in Oral Delivery of Macromolecular Drugs: Barriers, Strategies and Future Trends, A. Bernkop-Schnürch, Ed., Springer US, New York, NY, 2009, p. 169.

[56] H. Takeuchi, H. Yamamoto, Y. Kawashima, Adv Drug Deliver Rev 2001, 47, 39.

[57] H. Takeuchi, Y. Matsui, H. Yamamoto, Y. Kawashima, Journal of Controlled Release 2003, 86, 235.

[58] H. Takeuchi, J. Thongborisute, Y. Matsui, H. Sugihara, H. Yamamoto, Y. Kawashima, Adv Drug Deliver Rev 2005, 57, 1583.

[59] H. Hägerström, M. Paulsson, K. Edsman, European Journal of Pharmaceutical Sciences 2000, 9, 301.

[60] A. Bernkop-Schnürch, Adv Drug Deliver Rev 2005, 57, 1569.

[61] A. Bernkop-Schnürch, V. Schwarz, S. Steininger, Pharm Res-Dordr 1999, 16, 876.

[62] V. M. Leitner, G. F. Walker, A. Bernkop-Schnürch, European Journal of Pharmaceutics and Biopharmaceutics 2003, 56, 207.

[63] C. Müller, A. Bernkop-Schnürch, "Thiomers", in Mucoadhesive Materials and Drug Delivery Systems, John Wiley \& Sons, Ltd, 2014, p. 255.

[64] T. Schmitz, V. Grabovac, T. F. Palmberger, M. H. Hoffer, A. Bernkop-Schnürch, Int J Pharmaceut 2008, 347, 79.

[65] C. E. Kast, A. Bernkop-Schnürch, Biomaterials 2001, 22, 2345.

[66] C. Muller, D. Rahmat, F. Sarti, K. Leithner, A. Bernkop-Schnurch, Journal of Materials Chemistry 2012, 22, 3899.

[67] K. Kafedjiiski, A. H. Krauland, M. H. Hoffer, A. Bernkop-Schnürch, Biomaterials 2005, 26,819 .

[68] A. Bernkop-Schnürch, M. Hornof, T. Zoidl, Int J Pharmaceut 2003, 260, 229.

[69] S. Duggan, H. Hughes, E. Owens, E. Duggan, W. Cummins, O. O' Donovan, Int J Pharmaceut 2016, 499, 368.

[70] C. O. Ibie, C. J. Thompson, R. Knott, Colloid and Polymer Science 2015, 293, 1737.

[71] T. A. Sonia, C. P. Sharma, Journal of Biomedical Nanotechnology 2013, 9, 590. 
[72] F. Sarti, A. Staaf, D. Sakloetsakun, A. Bernkop-Schnürch, European Journal of Pharmaceutics and Biopharmaceutics 2010, 76, 421.

[73] A. Bernkop-Schnürch, S. Steininger, Int J Pharmaceut 2000, 194, 239.

[74] A. Bernkop-Schnürch, C. E. Kast, M. F. Richter, Journal of Controlled Release 2001, 71, 277.

[75] A. Bernkop-Schnürch, S. Scholler, R. G. Biebel, Journal of Controlled Release 2000, 66, 39.

[76] A. Bernkop-Schnürch, A. E. Clausen, M. Hnatyszyn, Int J Pharmaceut 2001, 226, 185.

[77] J. Iqbal, G. Shahnaz, S. Dünnhaupt, C. Müller, F. Hintzen, A. Bernkop-Schnürch, Biomaterials 2012, 33, 1528.

[78] M. Ijaz, A. Bernkop-Schnürch, Expert Opinion on Drug Delivery 2015, 12, 1269.

[79] L. Solhi, S. A. Schönbichler, S. Dünnhaupt, J. Barthelmes, H. Friedl, C. W. Huck, A. Bernkop-Schnürch, Biomacromolecules 2012, 13, 3054.

[80] M. T. Cook, S. A. Schmidt, E. Lee, W. Samprasit, P. Opanasopit, V. V. Khutoryanskiy, Journal of Materials Chemistry B 2015, 3, 6599.

[81] J. H. Waite, T. J. Housley, M. L. Tanzer, Biochemistry 1985, 24, 5010.

[82] J. H. Waite, International Journal of Adhesion and Adhesives 1987, 7, 9.

[83] J. H. Waite, N. H. Andersen, S. Jewhurst, C. Sun, The Journal of Adhesion 2005, 81, 297.

[84] H. Lee, N. F. Scherer, P. B. Messersmith, Proceedings of the National Academy of Sciences 2006, 103, 12999.

[85] Q. Lin, D. Gourdon, C. Sun, N. Holten-Andersen, T. H. Anderson, J. H. Waite, J. N. Israelachvili, Proceedings of the National Academy of Sciences 2007, 104, 3782.

[86] L. Ninan, J. Monahan, R. L. Stroshine, J. J. Wilker, R. Shi, Biomaterials 2003, 24, 4091.

[87] J. H. Ryu, S. Hong, H. Lee, Acta Biomaterialia 2015, 27, 101.

[88] K. Kim, K. Kim, J. H. Ryu, H. Lee, Biomaterials 2015, 52, 161.

[89] A. E. Ivanov, "Boronate-Containing Polymers", in Mucoadhesive Materials and Drug Delivery Systems, John Wiley \& Sons, Ltd, 2014, p. 279.

[90] G. Springsteen, B. Wang, Tetrahedron 2002, 58, 5291.

[91] B. Pappin, M. J. Kiefel, T. A. Houston, "Boron-Carbohydrate Interactions", in Carbohydrates - Comprehensive Studies on Glycobiology and Glycotechnology, C.-F. Chang, Ed., InTech, Rijeka, 2012, p. Ch. 03.

[92] A. Liu, S. Peng, J. C. Soo, M. Kuang, P. Chen, H. Duan, Analytical Chemistry 2011, 83, 1124.

[93] H. Otsuka, E. Uchimura, H. Koshino, T. Okano, K. Kataoka, Journal of the American Chemical Society 2003, 125, 3493.

[94] S. A. Asher, V. L. Alexeev, A. V. Goponenko, A. C. Sharma, I. K. Lednev, C. S. Wilcox, D. N. Finegold, Journal of the American Chemical Society 2003, 125, 3322.

[95] W. M. J. Ma, M. P. Pereira Morais, F. D'Hooge, J. M. H. van den Elsen, J. P. L. Cox, T. D. James, J. S. Fossey, Chemical Communications 2009, 532.

[96] A. Matsumoto, R. Yoshida, K. Kataoka, Biomacromolecules 2004, 5, 1038.

[97] A. Matsumoto, H. Cabral, N. Sato, K. Kataoka, Y. Miyahara, Angewandte Chemie International Edition 2010, 49, 5494.

[98] S. Liu, C. N. Chang, M. S. Verma, D. Hileeto, A. Muntz, U. Stahl, J. Woods, L. W. Jones, F. X. Gu, Nano Research 2015, 8, 621.

[99] O. M. Kolawole, W. M. Lau, V. V. Khutoryanskiy, Journal of Pharmaceutical Sciences 2019.

[100] Y. E. Aguirre-Chagala, J. L. Santos, B. A. Aguilar-Castillo, M. Herrera-Alonso, ACS Macro Letters 2014, 3, 353.

[101] Y. Xu, K. Sato, K. Mawatari, T. Konno, K. Jang, K. Ishihara, T. Kitamori, Advanced Materials 2010, 22, 3017. 
[102] S. Kitano, Y. Koyama, K. Kataoka, T. Okano, Y. Sakurai, Journal of Controlled Release 1992, 19, 161.

[103] G. Prosperi-Porta, S. Kedzior, B. Muirhead, H. Sheardown, Biomacromolecules 2016, $17,1449$.

[104] M. Davidovich-Pinhas, H. Bianco-Peled, "Acrylated Polymers", in Mucoadhesive Materials and Drug Delivery Systems, John Wiley \& Sons, Ltd, 2014, p. 309.

[105] M. Davidovich-Pinhas, H. Bianco-Peled, Journal of Materials Science: Materials in Medicine 2010, 21, 2027.

[106] T. Eshel-Green, H. Bianco-Peled, Colloids and Surfaces B: Biointerfaces 2016, 139, 42. [107] R. P. Brannigan, V. V. Khutoryanskiy, Colloids and Surfaces B: Biointerfaces 2017, $155,538$.

[108] N. N. Porfiryeva, S. F. Nasibullin, S. G. Abdullina, I. K. Tukhbatullina, R. I. Moustafine, V. V. Khutoryanskiy, Int J Pharmaceut 2019, 562, 241.

[109] Y. Shitrit, H. Bianco-Peled, Int J Pharmaceut 2017, 517, 247.

[110] O. M. Kolawole, W. M. Lau, V. V. Khutoryanskiy, Int J Pharmaceut 2018, 550, 123.

[111] P. Tonglairoum, R. P. Brannigan, P. Opanasopit, V. V. Khutoryanskiy, Journal of Materials Chemistry B 2016, 4, 6581.

[112] Y. Shtenberg, M. Goldfeder, A. Schroeder, H. Bianco-Peled, Carbohyd Polym 2017, $175,337$.

[113] D. B. Kaldybekov, P. Tonglairoum, P. Opanasopit, V. V. Khutoryanskiy, European Journal of Pharmaceutical Sciences 2018, 111, 83.

[114] N. Sahatsapan, T. Rojanarata, T. Ngawhirunpat, P. Opanasopit, P. Tonglairoum, Carbohyd Polym 2018, 202, 258.

[115] C. Menzel, M. Hauser, A. Frey, M. Jelkmann, F. Laffleur, S. K. Gotzfried, R. Gust, A. Bernkop-Schnurch, Eur J Pharm Biopharm 2019, 139, 161.

[116] C. Leichner, P. Wulz, R. A. Baus, C. Menzel, S. K. Gotzfried, R. Gust, A. BernkopSchnurch, Mol Pharm 2019, 16, 1211.

[117] M. Messina, H. S. Dua, Int Ophthalmol 2019, 39, 693.

[118] S. Moulay, Orient J Chem 2018, 34, 1153.

[119] W. L. A. Brooks, B. S. Sumerlin, Chem Rev 2016, 116, 1375. 